Article

\title{
Accumulation Patterns of Six Pyrethrin Compounds across the Flower Developmental Stages-Comparative Analysis in Six Natural Dalmatian Pyrethrum Populations
}

\author{
Martina Grdiša ${ }^{1,2} \mathbb{D}^{\text {, Nina Jeran }}{ }^{1, *}$, Filip Varga ${ }^{1,2} \mathbb{D}$, Tatjana Klepo ${ }^{3} \mathbb{D}$, Tonka Ninčević ${ }^{4}$ and Zlatko Šatović ${ }^{1,2} \mathbb{D}$ \\ 1 Department of Seed Science and Technology, Faculty of Agriculture, University of Zagreb, Svetošimunska C. 25, \\ 10000 Zagreb, Croatia; mgrdisa@agr.hr (M.G.); fvarga@agr.hr (F.V.); zsatovic@agr.hr (Z.Š.) \\ 2 Centre of Excellence for Biodiversity and Molecular Plant Breeding (CoE CroP-BioDiv), Svetošimunska C. 25, \\ 10000 Zagreb, Croatia \\ 3 Center of Pomology, Croatian Agency for Agriculture and Food, Zvonimirova 14 A, 21210 Solin, Croatia; \\ tatjana.klepo@hapih.hr \\ 4 Department for Plant Sciences, Institute for Adriatic Crops and Karst Reclamation, Put Duilova 11, \\ 21000 Split, Croatia; Tonka.Nincevic@krs.hr \\ * Correspondence: njeran@agr.hr; Tel.: +385-1-2393-845
}

check for updates

Citation: Grdiša, M.; Jeran, N.; Varga, F.; Klepo, T.; Ninčević, T.; Šatović, Z. Accumulation Patterns of Six Pyrethrin Compounds across the Flower Developmental Stages-Comparative Analysis in Six Natural Dalmatian Pyrethrum Populations. Agronomy 2022, 12, 252. https://doi.org/10.3390/ agronomy12020252

Academic Editors: Antonios Chrysargyris, Helen D. Skaltsa and Maria Konstantopoulou

Received: 16 December 2021

Accepted: 17 January 2022

Published: 19 January 2022

Publisher's Note: MDPI stays neutral with regard to jurisdictional claims in published maps and institutional affiliations.

Copyright: (c) 2022 by the authors Licensee MDPI, Basel, Switzerland. This article is an open access article distributed under the terms and conditions of the Creative Commons Attribution (CC BY) license (https:// creativecommons.org/licenses/by/ $4.0 /)$.

\begin{abstract}
Pyrethrin is a specialized metabolite of Dalmatian pyrethrum (Tanacetum cinerariifolium (Trevir.) Sch. Bip.), Asteraceae, known worldwide as an effective bioinsecticide. It consists of six active compounds: Pyrethrin I and II, cinerin I and II, and jasmolin I and II. Pyrethrin accumulates mainly in the flower heads and its content depends on numerous factors, such as the flower developmental stage. This study aims to investigate the accumulation patterns of six pyrethrin compounds in the flower heads of Dalmatian pyrethrum over the eight developmental stages (FS1 to FS8), and to make a comparison in six natural populations. Ultrasound assisted extraction was used to extract the pyrethrin, while qualitative and quantitative analysis was performed by High performance liquid chromatography. The accumulation patterns of different pyrethrin compounds were generally similar and also synchronous between different populations, while the pyrethrin I/pyrethrin II ratio showed irregular patterns. In all populations studied, the highest increase of all compounds was observed from FS1 to FS2. Their concentration continuously increased, reaching the highest values at FS4 stage (2-5 rows of open disc flowers), and generally decreased gradually towards FS6 or FS7 and then stagnated until the FS8 stage. Despite the very similar accumulation pattern of pyrethrin compounds in the different populations, the significant differences in their content suggest a different genetic background. Knowledge of the dynamics of pyrethrin compounds accumulation across flower development stages is valuable for determining the optimal harvest time of pyrethrum flower heads.
\end{abstract}

Keywords: Tanacetum cinerariifolium; Asteraceae; pyrethrin; harvest time

\section{Introduction}

The biosynthesis and accumulation of plant specialized metabolites (also known as secondary metabolites) are subject to qualitative and quantitative variations depending on the influence of numerous factors such as genotype, environmental factors [1,2], cultivation practices, agrotechnical processes, and postharvest procedures including storage [3], sample preparation techniques, and extraction methods [4].

Pyrethrin is a specialized metabolite of Dalmatian pyrethrum (Tanacetum cinerariifolium (Trevir.) Sch. Bip), Asteraceae, distributed along the eastern Adriatic coast and mountains in the hinterland of Croatia, Bosnia and Herzegovina, Montenegro, and Albania [5]. This perennial herbaceous plant species forms dense bushes from 30 to $70(100) \mathrm{cm} \mathrm{high}$. Numerous annual shoots end up with a single flower head, consisting of yellow disk florets in the center surrounded with white ray florets. Pyrethrins, the insecticidal compounds, 
are predominantly biosynthesized in the flower heads, most of which (about 94\%) is accumulated in the achenes [6]. More accurately, the highest concentrations are found on the pericarp of achenes, which is covered with glandular trichomes where a number of pyrethrin biosynthetic pathways reactions occur [7].

Pyrethrin consists of six chemically related compounds: Pyrethrin I and II, cinerin I and II, and jasmolin I and II. Pyrethrin I and II are present in the highest amount and are the main factors of the insecticidal activity of pyrethrum extract, and the ratio of these two components is the indicator of its insecticidal potential [8]. Pyrethrin has been commercially exploited and used since the 19th century [9]. The use of this natural insecticide has increased in recent decades due to its very low toxicity to humans combined with the high effectiveness against a broad range of insect species [10], together with the increasing awareness of the negative effects of synthetic pesticides. Dalmatian pyrethrum is commercially cultivated in different parts of the world, mainly in East African countries, Australia, and China [11-13].

Total pyrethrin content in the dry flower weight in samples of natural Dalmatian pyrethrum populations was estimated to range from 0.36 to $1.3 \%$ [14], or 0.10 to $1.35 \%$ on the level of individuals [15]. In produced commercial cultivars, e.g., in Tasmania, the total pyrethrin content was reported to range from about 1.8 to $2.5 \%$ [16], while the reported content in breeding lines in Kenya and the USA, was up to 3.0\% [17].

The biosynthesis and accumulation of pyrethrin is highly dependent on a variety of factors such as genotype $[15,18]$, morphological traits mainly related to floral characteristics [17,19-22], as well as environmental factors and climatic conditions [23,24]. Its content in the dry flower weight also depends on the extraction methods [25-29], storage conditions [16], drying methods [16,30,31], and agrotechnical methods applied [32] including the harvest time [33-35].

Pyrethrin content is significantly positively correlated with the diameter of the disc flower [21] that determines flower shape and size. Moreover, pyrethrin accumulation is closely related to the number [36] and development [37] of oil glands in the flower. The glands are fully developed when the pyrethrin content reaches maximum, while they collapse in the overblown stage when pyrethrin content decreases [37]. In the recent study by Suraweera et al. [38], flower size, flower head diameter, number of achenes, achene size, number of trichomes, and rate of pyrethrin accumulation were found to directly influence the final pyrethrin yield per flower. Aforementioned characteristics are related to the process of flower maturation. Head $[6,39]$ described eight flower head developmental stages and his classification was further slightly modified in the work of Bhat and Menary [34] and Potts and Menary [40]. The modification by Fulton [41] refers to 10 flower developmental stages. A single pyrethrum plant produces a large number of flower heads, and the stage of flower maturity may vary among flowers at a given time. Therefore, Potts and Menary [40] introduced the flower maturity index (FMI) to estimate the average flower maturity stage at the crop level (FMI 100-800 correspond to stages 1 to 8 from Head [6]).

Flower development stages and their correlation with pyrethrin content have been studied by several authors $[6,17,33-35,42,43]$. It was observed that in a highly variable seed population, pyrethrin content in flowers generally increased from the closed bud stage to the peak level when most of the disc florets had opened [33,42]. Gnadinger and Corl [43] observed that in fully mature flower samples (dry flower heads and seeds suitable for collection), the percentage of pyrethrin in dry flower weight is four times higher than in the unexpanded buds. Bhat and Menary [34] describe the stage when $3 / 4$ of the disc florets had opened as is generally the optimum stage for pyrethrin content. However, they also emphasize that different clones (genotypes) deviate from this rule, as also observed in other studies, together with the considerable variation in the shape of the pyrethrin accumulation curve between different clones [17,33-35]. These studies on pyrethrin accumulation in different stages of Dalmatian pyrethrum flower development were mainly conducted on various clones of cultivated pyrethrum and focused on the 
evaluation of total pyrethrin content. The only study to date that examined concentration changes of individual pyrethrin compounds dates from the 1960s [6]. The study was carried out on one clone with a very small sample size and used the analytical methods available at the time. The more recent study by Suraweera et al. [32] analyzed the change in pyrethrin I, pyrethrin II, and total pyrethrin content, also on a clonal population. A recent detailed study of pyrethrin content and composition of natural Dalmatian pyrethrum populations [15] revealed high chemical diversity within and between populations. It was of further interest to determine whether some diversity also exists in the accumulation patterns of pyrethrin compounds between different natural Dalmatian pyrethrum populations.

The aim of this study was therefore to determine a more detailed pattern of change in the content of each of the six active pyrethrin compounds and in the pyrethrin I to pyrethrin II ratio in Dalmatian pyrethrum flowers during the different developmental stages of the flowering cycle. The intention was to comparatively analyze pyrethrins accumulation patterns among populations with different genetic backgrounds. The study was conducted on a sample of six natural Dalmatian pyrethrum populations distributed across the species native range, and advanced analytical methods were used. The data on the dynamics of pyrethrin compounds accumulation at different stages of flower development are valuable for determining the optimal harvest time of pyrethrum flower heads. The results obtained will be useful for future breeding programs based on the utilization of natural populations with a broad genetic base, aimed at obtaining a high-quality pyrethrum extract that meets market requirements.

\section{Materials and Methods}

\subsection{Plant Material}

The seeds were collected from six Dalmatian pyrethrum natural populations (Table 1; Figure 1) and grown in a field experiment at the experimental station 'Maksimir' of the Department of Seed Science and Technology, the University of Zagreb Faculty of Agriculture $\left(45.83^{\circ} \mathrm{N}, 16.03^{\circ} \mathrm{E}\right)$. The seeds of the sampled populations are part of the Collection of Medicinal and Aromatic Plants, maintained at the Department of Seed Science and Technology, the University of Zagreb Faculty of Agriculture. Seedlings were planted according to the common agricultural practice, without irrigation and fertilization. Flower heads were collected from altogether 120 individuals from the six populations (20 per population), and were combined into representative population samples in two replicates for further chemical analysis.

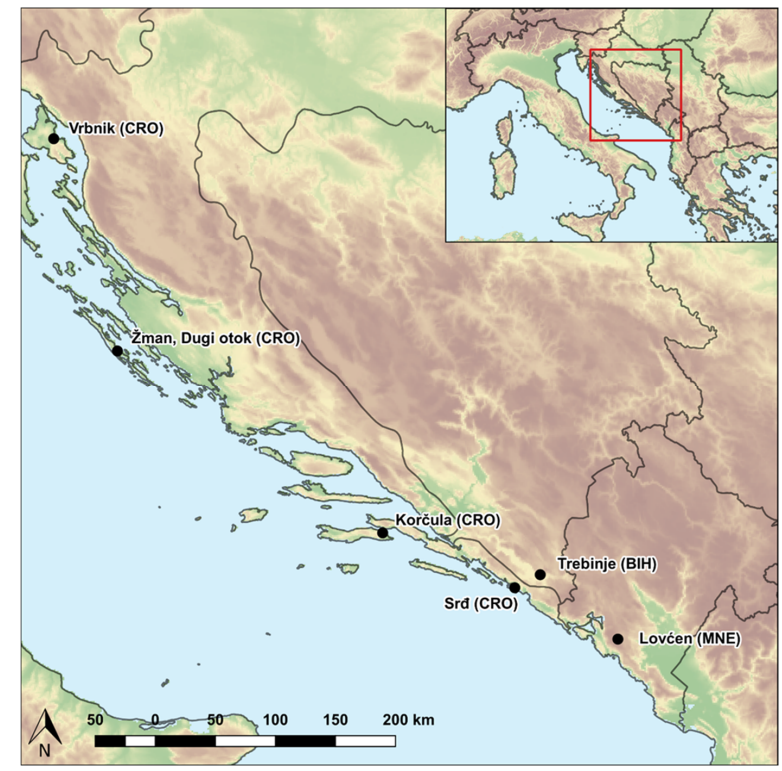

Figure 1. Sampling locations of the six natural Dalmatian pyrethrum populations. 
Table 1. Geographical data of sampling locations of Dalmatian pyrethrum.

\begin{tabular}{lclcc}
\hline No. & ACCENUMB $^{\text {a }}$ & Population & Latitude (N) & Longitude (E) \\
\hline P1 & MAP02970 & Vrbnik, Krk (CRO) & $45.07^{\circ}$ & $14.66^{\circ}$ \\
P2 & MAP02959 & Žman, Dugi otok (CRO) & $43.94^{\circ}$ & $15.14^{\circ}$ \\
P3 & MAP02824 & Korčula (CRO) & $42.95^{\circ}$ & $17.12^{\circ}$ \\
P4 & MAP02966 & Srđ (CRO) & $42.65^{\circ}$ & $18.11^{\circ}$ \\
P5 & MAP02969 & Trebinje (BIH) & $42.72^{\circ}$ & $18.30^{\circ}$ \\
P6 & MAP02979 & Lovćen (MNE) & $42.37^{\circ}$ & $18.88^{\circ}$ \\
\hline
\end{tabular}

a Accession number from Croatian Plant Genetic Resources Database, Zagreb, Croatia, available at the CPGRD (https:/ / cpgrd.hapih.hr, accessed on 10 May 2021).

Flower heads were sampled at eight different flower developmental stages, slightly modified from those defined by Head [6], referred to as FS1-FS8, in the further text (Table 2).

Table 2. Flower developmental stages of Dalmatian pyrethrum.

\begin{tabular}{|c|c|c|}
\hline Phase & Image & Description \\
\hline FS1 & & well-developed closed buds \\
\hline FS2 & & ray florets emerging from the bud \\
\hline FS3 & & 1-2 rows of disc florets open \\
\hline FS4 & & $2-5$ rows of disc florets open \\
\hline FS5 & & all disc florets open \\
\hline FS6 & & all florets open; half of them brown \\
\hline
\end{tabular}


Table 2. Cont.

\begin{tabular}{ccc}
\hline Phase & Description \\
\hline FS7 & ray florets dry; disc florets intact but with \\
little color
\end{tabular}

\subsection{Extraction and Quantification of Pyrethrins}

\subsubsection{Standards and Reagents}

The acetone, p.a. used as an extraction solvent was purchased from Merck (Darmstadt, Germany). Ultrapure water used for the mobile phase for HPLC analysis was prepared by a Synergy ${ }^{\circledR}$ UV Water Purification System (Merck Milipore, Darmstadt, Germany). The analytical pyrethrin standard (Pyrethrum extract Pestanal ${ }^{\circledR}$ ) and the internal standard $4^{\prime}$-methoxyflavanone were purchased from Sigma-Aldrich (Steinheim, Germany). The mass fractions of each pyrethrin compound in the Pestanal ${ }^{\circledR}$ standard were as follows: $2.4293 \%$ for cinerin II, $12.4767 \%$ for pyrethrin II, $0.7981 \%$ for jasmolin II, $3.1438 \%$ for cinerin I, $20.4048 \%$ for pyrethrin I, and $1.1758 \%$ for jasmolin I. Stock standard solution (c $=5 \mathrm{mg} / \mathrm{mL}$ ) was prepared by dissolving $100 \mathrm{mg}$ of the pyrethrum mixture (Pestanal ${ }^{\circledR}$ ) in $20 \mathrm{~mL}$ acetonitrile and stored in the dark at $4{ }^{\circ} \mathrm{C}$. The six working standard solutions of different concentrations $(0.125,0.25,0.50,1.00,2.00$, and $4.00 \mathrm{mg} / \mathrm{mL})$ were prepared by an appropriate dilution of the stock standard solution in acetonitrile.

\subsubsection{Ultrasound Assisted Extraction}

Ultrasound extraction was performed as described in Babić et al. [44]. Before extraction, the flowers of Dalmatian pyrethrum were dried and powdered. The $0.25 \mathrm{~g}$ of the plant material was accurately weighed and placed in the vessel containing $100 \mu \mathrm{L}$ of the internal standard $4^{\prime}$-methoxyflavanone $(c=5 \mathrm{mg} / \mathrm{mL})$ and $4.9 \mathrm{~mL}$ of acetone. The vessels were sealed and placed in an ultrasonic bath at a constant temperature of $50{ }^{\circ} \mathrm{C}$ for $60 \mathrm{~min}$ (Labsonic LBS2-10, FALC, Treviglio, Italy).

After extraction, the extracts were filtered through a filter with a pore diameter of $0.45 \mu \mathrm{m}$ (HPLC certified, Pall life Sciences, Port Washington, NY, USA).

\subsubsection{HPLC}

Detection and quantification of the six pyrethrin compounds was performed by high performance liquid chromatography coupled with diode array detector-ultraviolet/visible light detector-HPLC-DAD-UV/VIS (Agilent Technologies, Santa Clara, CA, USA) on a Zorbax SB C18 $250 \times 4.6 \mathrm{~mm}$, particle size $5 \mu \mathrm{m}$ (Agilent Technologies, Santa Clara, CA, USA). The mobile phase used in the chromatographic system was $0.1 \%$ phosphoric acid in MilliQ water (A) and acetonitrile (B) in gradient elution mode (Table 3).

The flow rate of the mobile phase was $1.4 \mathrm{~mL} / \mathrm{L}$, while the injection volume was $5 \mu \mathrm{L}$. The separated pyrethrin compounds were monitored by their absorbance at $225 \mathrm{~nm}$. For each of the pyrethrin compounds, calibration curves were generated using six working standard solutions of the pyrethrin mixture. Duplicate injections were performed for each solution and the peak area ratio of the analyte to that of the internal standard was plotted against the concentration of each compound. Chromatogram of HPLC analysis of the standard stock solution is provided as Supplementary Materials (Figure S1). 
Table 3. HPLC-DAD-UV/VIS mobile phase gradient elution conditions.

\begin{tabular}{ccc}
\hline Time (min) & A (\%) & B (\%) \\
\hline 0.00 & 40 & 60 \\
15.00 & 40 & 60 \\
25.00 & 20 & 80 \\
35.00 & 20 & 80 \\
35.10 & 40 & 60 \\
40.00 & 40 & 60 \\
\hline
\end{tabular}

\subsection{Data Analysis}

The MIXED procedure in SAS 9.4 (SAS Institute Inc., Cary, NC, USA) was utilized in the analysis of variance (ANOVA) with repeated measures [45]. A completely randomized block design (CRBD) was used to examine the effects of population, flowering stage (for repeated measures), and population-flowering stage interaction on pyrethrin content. The covariance structure was selected based on the Akaike information criterion with a correction for a small sample size (AICc), considering five types of structure of the covariance matrix: Unstructured (UN), variance components (VC), compound symmetric (CS), first order autoregressive (AR1), and Toeplitz (TOEP). The significance of differences in the levels of pyrethrin compounds in populations between and within flowering stages was performed using Tukey's honest significant difference post hoc test for partitioned F-tests (SLICE option).

\section{Results}

The optimal covariance matrix structure model was determined between five models. Since the lowest AICC values for all six pyrethrin compounds as well as total pyrethrin content and pyrethrin I/pyrethrin II (pyr I/pyr II) ratio were obtained for the variance components model (VC) (Table S1), this model was used for performing ANOVA with repeated measures for all eight variables.

\subsection{Total Pyrethrin Content}

Total pyrethrin content increased significantly over time from FS1 to FS4 in all populations studied (Figure 2). In FS1 (well-developed, closed buds), the average total pyrethrin content was $0.28 \%$ of flower dry weight (DW). From FS1 to FS2 (ray florets emerging from the bud), the total pyrethrin content increased by $97 \%$ on average, by $74-164 \%$ per population, and this increase was statistically significant, except in P3 Korčula. The highest increase in total pyrethrin content from FS1 to FS2 was recorded in P6 Lovćen (164\%), followed by P4 Srd (149\%). From FS2 to FS3 (1-2 rows of open disc flowers), the average increase in total pyrethrin content was 37\% (6-109\%), while from FS3 to FS4, it was 34\% on average (26-44\%). In FS4 (2-5 rows of disc florets open), the highest pyrethrin content was measured in all populations (average 1.01\% of flower DW), although in P6 Lovćen, P5 Trebinje, and P3 Korčula, this value did not differ significantly between FS3 and FS4, while in P4 Srd, there was no significant difference between FS4 and FS5. The maximum values of total pyrethrin content in studied populations ranged from $0.82-1.14 \%$. The highest value of $1.14 \%$ was observed in $\mathrm{P} 4 \mathrm{Srd}$, but was not significantly different from the other populations, except from P3 Korčula, where the highest total pyrethrin content was $0.82 \%$ of flower DW. From FS4 to FS5 (all disc florets open), a decrease in total pyrethrin content was observed in all populations, which was statistically significant except for P4 Srđ. From stage FS5 to FS6, the total pyrethrin content moderately decreased in all studied populations, after which the stagnation trend was noted towards FS8. From FS6 to FS8, no significant differences were observed among the populations and between the phases (Figure 2). 


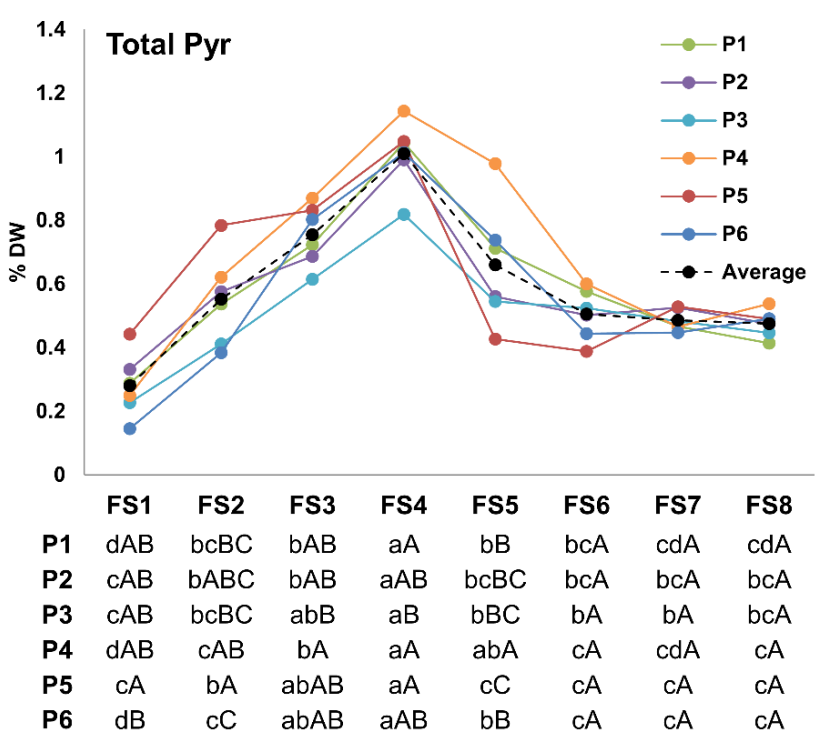

Figure 2. Content of total pyrethrin across the eight flower developmental stages in six Dalmatian pyrethrum populations. Lowercase letters refer to differences between phases in the same population, while uppercase letters refer to differences between populations within the same phase.

\subsection{Pyrethrin I and II}

The average value of pyrethrin I (pyr I) in FS1 was $0.14 \%$ of flower DW, ranging from $0.07 \%$ (P6 Lovćen) to $0.23 \%$ (P5 Trebinje) and it increased on average by $87 \%$ (56-163\%) from FS1 to FS2 (Figure 3a). The highest increase, by 163\%, was observed in P6 Lovćen (from 0.071 to $0.185 \%$ of flower DW), although without significance. Significant differences between the pyr I levels in FS1 and FS2 were observed only in P5 Trebinje and P4 Srđ. From FS2 to FS4, pyr I content continued to increase in all populations, until the peak of pyr I accumulation was reached in FS4. At this stage, P5 Trebinje had the highest pyr I content $(0.58 \%$ of flower DW), followed by P4 Srđ $(0.57 \%)$. These two values were not significantly different from each other nor from those of P6 Lovćen and P2 Žman. In addition, in P1 Vrbnik, P3 Korčula, P5 Trebinje, and P6 Lovćen, pyr I content in FS4 was not significantly different from the content noted in FS3. From FS4 to FS6, a decrease in pyr I content was observed in all studied populations. The difference was statistically significant between FS4 to FS5 (except in P1 Vrbnik and P4 Srd), and between FS5 to FS6 in populations P4 Srd and P6 Lovćen. From FS6 to FS8, pyr I content stagnated (slightly increased in P5 Trebinje) and no significant differences were observed, between stages nor between populations (Figure 3a).
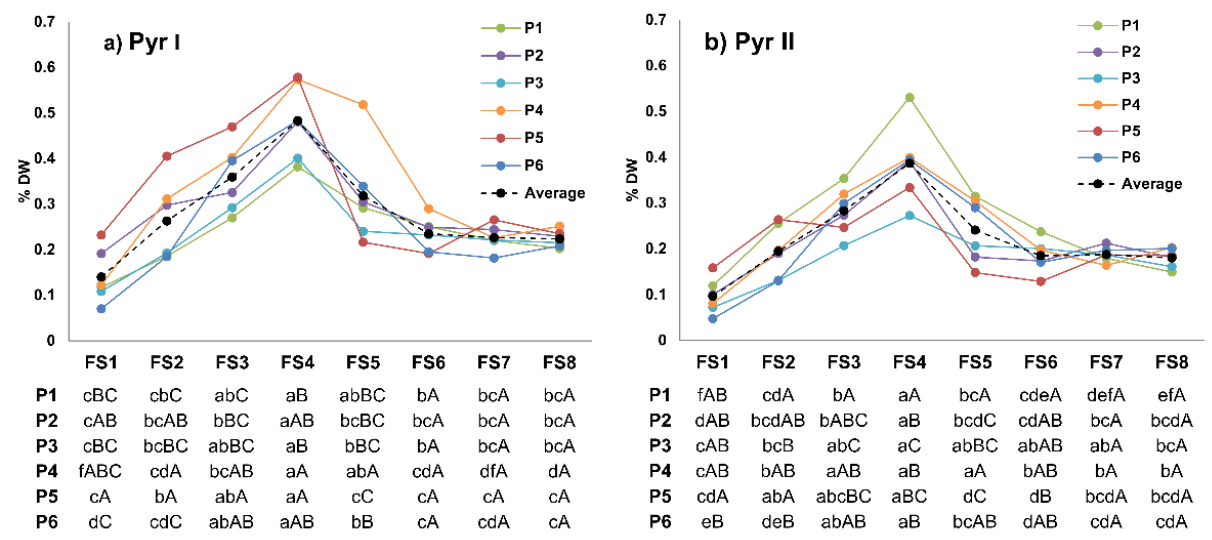

Figure 3. Content of (a) pyrethrin I and (b) pyrethrin II across the eight flower developmental stages in six Dalmatian pyrethrum populations. Lowercase letters refer to differences between phases in the same population, while uppercase letters refer to differences between populations within the same phase. 
As shown in Figure 3b, pyrethrin II (pyr II) followed the same accumulation pattern as pyr I. On average, pyr II content in FS1 was $0.09 \%$, and it ranged from $0.05 \%$ in P6 Lovćen to $0.16 \%$ in P5 Trebinje. The highest increase in pyr II content was observed from stage FS1 to FS2 in all populations, on average by $102 \%$, in a range from $67 \%$ to the highest increase of $175 \%$ observed in population P6 Lovcen, the population that had the lowest pyr II content in FS1. In the same population, the highest increase in pyr II content from FS2 to FS3 was also observed (129\%) and it was significant. From stage FS2 to FS3, pyr II content continued to increase in all populations except in P5 Trebinje where a slight decrease in pyr II content was observed (by 6\%). In stage FS4, the highest pyr II content was noted in all populations ( $0.39 \%$ of flower DW on average). Among them, population P1 Vrbnik was the most distinctive, where a pyr II content of $0.53 \%$ was measured and was significantly different from the pyr II content observed in other populations. The pyr II content in stage FS4 was significantly different from other stages only in P1 Vrbnik and P2 Žman. In other populations, it was not significantly different from pyr II content neither in FS2 and FS3 (P5 Trebinje), nor from FS3 and FS5 (P3 Korčula and P4 Srđ), nor from FS3 in P6 Lovćen. From FS4 to FS8, an average decrease in pyr II content of $46 \%$ was observed. In FS6, only populations P1 Vrbnik and P5 Trebinje significantly differed from each other in pyr II content. From FS6 to FS8, generally a stagnation in the pyr II content was observed and there were no significant differences between and within populations.

\subsection{Pyr I/pyr II Ratio}

The concentration curve of the pyr I/pyr II ratio across stages did not follow the same trend as individual compounds, and no regularities were observed between populations. Although the ratio varied over time, no significant differences were observed between the different stages in P3 Korčula, P4 Srd, and P6 Lovćen. In three of the studied populations (P2 Žman, P3 Korčula, and P6 Lovćen), the highest values of pyr I/pyr II ratio were observed in FS1. In P6 Lovćen and P3 Korčula, it was 1.49 and 1.51, respectively. The highest value of pyr I/pyr II ratio in this study, 1.92, was observed in FS1 in population P2 Žman and in FS3 in P5 Trebinje. This value differed significantly from the lowest value that was observed in FS8 (in P5 Trebinje), while in P2 Žman, it differed from stages FS3, FS4, FS7, and FS8. In P1 Vrbnik, the highest ratio was observed in FS8 (1.36) and it was significantly higher from that in FS2-FS4, while in P4 Srđ it was in FS5 (1.70). No significant differences were observed among the populations in FS6, FS7, and FS8 (Figure 4).

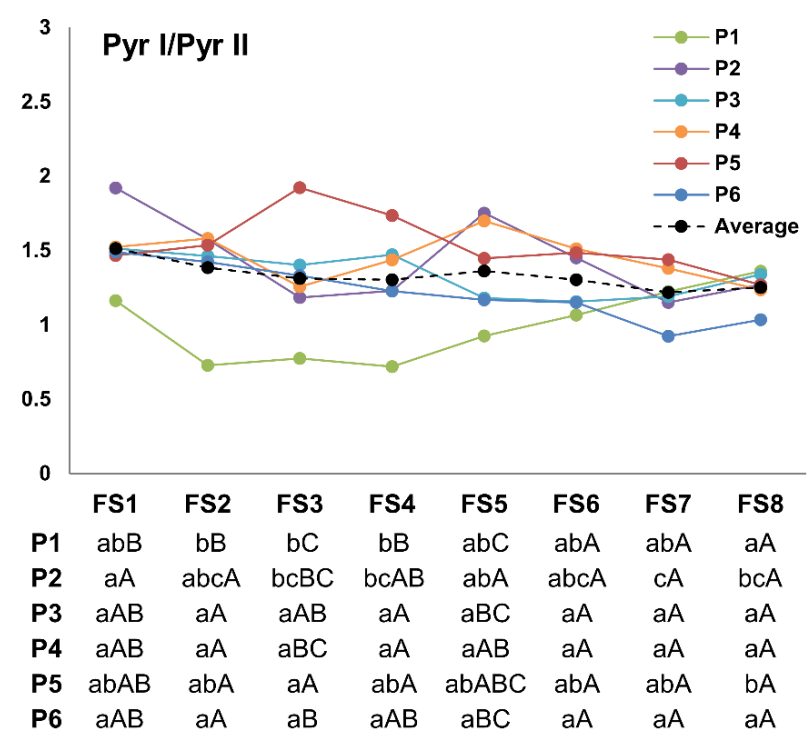

Figure 4. Pyrethrin I to pyrethrin II ratio across the eight flower developmental stages in six Dalmatian pyrethrum populations. Lowercase letters refer to differences between phases in the same population, while uppercase letters refer to differences between populations within the same phase. 


\subsection{Cinerin I and II}

In FS1, no significant differences in cinerin I (cin I) content were detected among the populations. The highest increase in cin I content was from FS1 to FS2 (average 128\%, 68-179\%). The highest cin I content was found at stage FS4 in all populations, while in P4 Srd, the same value was also observed in FS5 (0.07\%). At stage FS4, P4 Srd had significantly higher cin I content than other populations except P3 Korčula, while the difference at stage FS5 was significant compared to all populations. Cin I content in FS4 was not statistically different from stages FS2, FS3, FS5, and FS6 in P1 Vrbnik and P2 Žman; from FS3 and FS5 in populations P4 Srđ and P6 Lovćen; from stages FS2 and FS3 in P5 Trebinje, and from FS3 in P3 Korčula. After the peak in stage FS4, there was on average a decrease in the cin I content till FS7, and a stagnation from FS7 to FS8. The exception was in the P5 Trebinje where a slight increase was noted between FS5 and FS7 (Figure 5a).
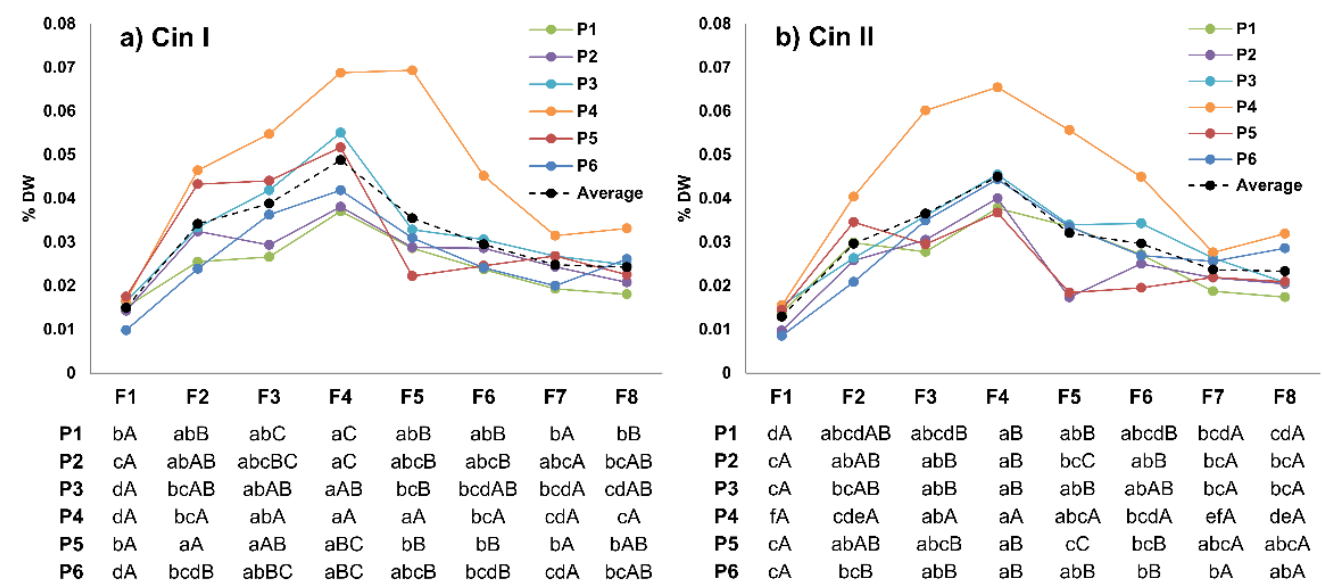

Figure 5. Content of (a) cinerin I and (b) cinerin II across the eight flower developmental stages in six Dalmatian pyrethrum populations. Lowercase letters refer to differences between phases in the same population, while uppercase letters refer to differences between populations within the same phase.

As for cin I, no significant differences were found in the content of cinerin II (cin II) among populations in FS1. The highest amounts of cin II were detected in the P4 Srd population at stages FS2-FS8 and were significantly higher in stages FS3-FS5 compared to all other populations. The highest increase in cin II content was observed from FS1 to FS2 (by $129 \%$ on average, $69-164 \%$ ), and the increase was significant in populations P2 Žman, P4 Srd, and P5 Trebinje. In all studied populations, the cin II content increased until stage FS4, where the highest cin II content was detected, on average $0.05 \%$ of flower DW, with a maximum of $0.07 \%$ in population P4 Srd. Nevertheless, the cin II content in FS4 did not differ significantly from stages FS3 and FS5 in P2 Žman and P5 Trebinje. From stage FS4 to later stages, a slight decrease in cin II content was observed till stage FS6, and a stagnation till FS8 when the average cin II content of flower DW was $0.02 \%$. The exception was again in P5 Trebinje where an increase was noted between FS5 and FS7. In FS5, populations did not differ significantly in cin II content, with the exception of P4 Srd. In FS1, FS7, and FS8 there were no significant differences in cin II content between the stages and studied populations (Figure 5b).

\subsection{Jasmolin I and II}

Jasmolin I (jas I) and jasmolin II (jas II) showed a similar pattern of accumulation in six populations studied (Figure $6 \mathrm{a}, \mathrm{b}$ ). Concentrations of jas II and jas I both increased on average by $91 \%$ (jas I by $65-140 \%$ and jas II by $65-174 \%$ ) from FS1 to FS2. Both active compounds continued to increase until the FS4 stage where the highest values were recorded, on average $0.020 \%$ of jas II and $0.026 \%$ of jas I in flower DW. The amounts of both jas I and jas II at stage FS4 were not significantly different from those at stage FS3, except the amount 
of jas II in P6 Lovćen. There was also no difference between the FS3 and FS2 stages in the content of jas II and jas I in populations P4 Srđ and P5 Trebinje, and also in jas II in P2 Žman. Furthermore, the content of jas II in FS5 was not significantly different from FS3, except in P2 Žman and P5 Trebinje. The highest jas I content was observed in P1 Vrbnik (0.033\% of flower DW) but was not significantly different from the content in P3 Korčula, P5 Trebinje, and P6 Lovćen. In FS4, jas II was also the highest in P1 Vrbnik (0.025\% of flower DW) but was not significantly different from the content observed in P6 Lovćen. Towards the FS7 stage of flower maturity, the levels of jas I and II gradually decreased. A slight increase in the amount of these two compounds was observed from stage FS7 to FS8 (except in P1 Vrbnik). However, no significant differences in the content of jas I were observed in stages between FS6 and FS8 within and between populations (Figure 6a).
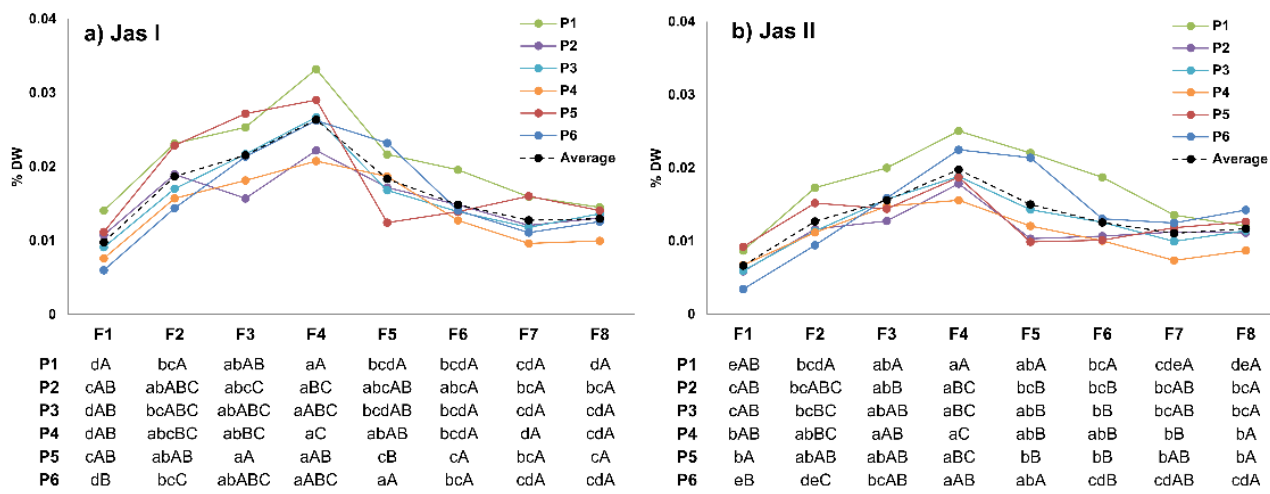

Figure 6. Content of (a) jasmolin I and (b) jasmolin II across the eight flower developmental stages in six Dalmatian pyrethrum populations. Lower case letters refer to differences between phases in the same population, while uppercase letters refer to differences between populations within the same phase.

\section{Discussion}

Understanding the optimal stage of flower development in relation to pyrethrin content is important from an agronomic and commercial perspective. This study reports quantitative analyzes of pyrethrin compounds and total pyrethrin content, as well as the pyr I/pyr II ratio in natural populations of Dalmatian pyrethrum at different flower developmental stages, using a slightly modified definition of flower stages from Head [6]. Possible differences between accumulation patterns and pyrethrin compounds content at different flowering stages were also investigated comparatively between the populations (Figures 2-6). The final objective of the study was to contribute to the knowledge of optimal production conditions by optimizing the harvest time to obtain a higher content of high-quality pyrethrin extract.

\subsection{Accumulation Patterns of Total Pyrethrin and Pyrethrin Compounds over Flowering Stages}

A rapid accumulation trend of all compounds occurs from FS1 to FS2, with an average increase of $87-129 \%$ per compound and an average increase of $97 \%$ in total pyrethrin content. On average, $55 \%$ of the maximum total pyrethrin content was already produced by FS2. Similar results were reported by Ramirez et al. [7], who found that $50 \%$ of the pyrethrin content was produced before the opening of the first disc florets (FS2), at a time when no embryos had yet formed. In addition, Suraweera et al. [32,38] found that the total pyrethrin concentration increased rapidly during the early flowering stages and at flower maturity index FMI 200 (corresponding to FS2 stage at individual level) 70\% of the concentration was reached at physiological maturity (corresponding to FS6). Moreover, according to the study by Suraweera et al. [32], more than half (59\%) of the total number of achenes present at physiological maturity was formed at the early stages of flower development. Since the number of achenes per flower showed a strong positive correlation with pyrethrin yield 
per flower, it was concluded that early flower development plays an important role in determining the final pyrethrin yield per flower.

A general regularity in the accumulation pattern between pyrethrin compounds and between different populations was observed in the natural Dalmatian pyrethrum populations studied. From the FS1 to FS4 stage, a continuous increase in the content of each compound was observed. At the FS4 stage (2-5 rows of open disc flowers), concentrations of all six pyrethrin compounds and total pyrethrin content were the highest in all populations studied. In P4 Srd, cin I content had the same value in both FS4 and FS5 stages. After the maximum value at the FS4 stage, a decrease towards the FS6 or FS7 stage was observed, after which the concentrations of pyrethrin compounds and total pyrethrin content stagnated (or even slightly increased in the case of jas I and II) between FS7 and FS8. From FS4 to FS5, total pyrethrin content decreased on average by $35 \%$ (up to 59\%), from FS5 to FS6 by a further $23 \%$, from FS6 to FS7 by $4 \%$ and from FS7 to FS 8 by an average of $2 \%$. The population P5 Trebinje showed a slightly different pattern, there was a slight increase from FS2 to FS3 in five of the compounds, an increase from FS5 to FS6 in four of the compounds and an increase from FS6 to FS7 in all six compounds.

Our results are in agreement with the observations of Head [6], who analyzed the change in concentration of all six pyrethrin compounds in a pyrethrum clone. The author states that the accumulation of pyrethrins during flower development occurs in two phases, a phase in which the pyrethrin concentration increases (FS1 to FS4) and a stationary phase in which the absolute content per flower head has reached its maximum and remains almost constant (FS5 to FS7). However, due to the constant growth of flower head tissue until FS7, the accumulation curve (\% of flower DW) starts to decrease from FS4 towards FS7. Therefore, the author concludes that the pyrethrin content in flower DW is at optimum in FS4 (about 3 rows of florets open), observing the same trend for four compounds (pyrethrins I and II and cinerins I and II), while jasmolins I and II had a peak in FS5 (which was not the case in our study). At the last stage of flower development, FS8, Head [6] noted a decrease in pyrethrins content per flower head. In the absence of studies on the causes of this decline, Groom [46] suggests the possibility that pyrethrins are actively metabolized in maturing flowers and pyrethrin content may depend on the balance between rates of synthesis and catabolism.

Our study confirms the generally accepted view that flowers are mature and ready for harvest when $1 / 2$ to $3 / 4$ of the disc florets have opened [17] i.e., at stage FS4 [6,34]. Although this rule applies to a highly variable seed population and to many clones that also peak at the FS4 stage [34], some clones have been observed to peak at other stages between FS2 and FS6. It has also been shown that different clones have a characteristic pyrethrin accumulation pattern [33-35,37]. Parlevliet [33] found that in most clones the maximum pyrethrin content is reached between the stage when 4-6 rows of disc florets have opened and the stage when all disc florets except the central ones were open, corresponding to the stage between FS4 and FS5 of Head [6], while in some clones the maximum is reached in the early overblown condition (corresponding to FS6). The results of Ikahu and Ngugi [35] show that in most clones the maximum pyrethrin content is reached at the FS5 stage, when almost all disc florets were opened. In Tasmanian clones, maximum pyrethrin content is reached on a crop level between FMI 400 and 600, and then gradually decreases as flowers mature and seeds develop. Therefore, the optimum time for flower harvesting is between FS4 ( $1 / 3$ to $2 / 3$ of the diameter of the disc with florets open) and FS6 (all florets open and up to half of the disc area are brown) [40]. Comparable results were obtained by Suraweera et al. [32], where maximum total pyrethrin and pyr II concentrations were observed at physiological maturity (FMI 600) in the dryland condition group (comparable to the populations in our study), while the pyr I concentration reached its maximum at FMI 500.

The different flower developmental stages FS2-FS7 (bud to overblown stage) are associated with the expression of different genes for the enzymes of the pyrethrin biosynthetic pathway. In particular, TcCDS, a key enzyme for the biosynthesis of the acid component of 
pyrethrins [47]; TcLOX1 involved in the biosynthesis of the alcohol moiety [48]; and TcGLIP, responsible for the final esterification step in pyrethrin biosynthesis [7]. Gene expressions of TcCDS, TcGLIP [7], and TcLOX1 genes [48] show a consistently similar expression pattern during flower development. At stage FS2, before the first disc florets open, when pyrethrin compound levels increase rapidly and $50 \%$ of pyrethrins are already produced, a peak transcription of TcCDS, TcGLIP, and TcLOX1 occurs. In the developmental stages FS2 to FS5, when pyrethrins accumulate, their expression is high but gradually decreases, while in the later stages, FS6 and FS7, their expression sharply decreases as the flower matures and pyrethrin content reaches its maximum $[7,48]$.

In this study, the maximum values of total pyrethrin content in the six populations studied, observed at the stage FS4, ranged from 0.82 (observed in P3 Korčula) to 1.14\% of flower DW (observed in P4 Srd). This range is somewhat lower than in the previous studies of natural Dalmatian pyrethrum populations, where the total pyrethrin content in different populations ranged from 0.36 to $1.3 \%$ [14] and from 0.10 to $1.35 \%$ as determined at the individual level in the most recent detailed analysis [15].

In addition to the total pyrethrin content, the quality of the pyrethrin extract is determined by the pyr I/pyr II ratio. In previous analyses of pyrethrin content in natural Dalmatian pyrethrum populations, the pyr I/pyr II ratio was reported to range from 0.64 to 3.33 at the population level [14] and from 0.21 to 5.88 at the individual level [15], while a range of 0.47 to 3.5 [17] was reported for commercial cultivars. In contrast to the general synchronicity in the accumulation of six pyrethrin compounds across flowering stages in different populations observed in this study, there was no regular pattern in the change of the pyr I/pyr II ratio. In general, with few exceptions in two of the populations, no significant differences in the pyr I/pyr II ratio were observed across the different developmental stages in the studied populations. In three of the studied populations, the highest values of pyr I/pyr II ratio were observed in FS1. The maximal highest value of the pyr I/pyr II ratio observed in this study, 1.92, was found in FS1 in the population of P2 Žman and in FS3 in P5 Trebinje. Previously, it was presumed that pyr II increases and the ratio of pyr I/pyr II decreases towards later developmental stages, due to the biochemical conversion of pyrethrins I to pyrethrins II when the flower reaches maturity [7]. However, these presumptions were not confirmed in our study, as the concentrations of both pyr I and pyr II decreased towards the later flowering stages. Thus, no significant changes in the ratio of pyr I/pyr II were observed throughout the flower developmental stages, except for the few cases in the populations mentioned above.

\subsection{Variability among Studied Populations}

Although pyrethrin compounds followed very similar accumulation patterns over time in the populations studied, significant differences in their content were found between stages FS1-FS6 among some of the populations. In general, at the later stages (FS7-FS8), there were no significant differences in the contents of six compounds between populations, except for the significant difference in the content of cin I at stage FS8 and jas II at stage FS7 in populations P1 Vrbnik and P4 Srd, respectively. In addition, the contents of pyr I and jas I, as well as the total pyrethrin content and pyr I/pyr II ratio, did not differ significantly between the populations at stages FS6 to FS8. The contents of cin I and cin II were also not significantly different between populations at stages FS1, FS7, and FS8. It has already been found that both the pyrethrin composition and the pyr I/pyr II ratio in mature pyrethrum flowers vary widely and are characteristic of particular clones (genotypes) [49]. It has also been observed that different pyrethrum clones show a characteristic pattern of pyrethrin accumulation [17,33-35], so the accumulation pattern is attributed to genetic control. Parlevliet [33] found that the patterns of pyrethrin accumulation were similar in the same clones at the two sites with different environmental conditions, confirming the predominant influence of a genetic background. Therefore, the optimum harvesting stage must be determined individually for each clone [17]. Although a variation in the pattern of pyrethrin accumulation appears to have a genetic component, Groom [46] 
noted that no differences in optimum harvest stage were observed between clonal or seedling cultivars under growing conditions in Tasmania. Groom [46] estimated moderate heritability (0.24-0.34) for components of pyrethrin content and concluded that considerable phenotypic variation in the pattern of pyrethrin accumulation appears to be driven by both genetic and environmental factors.

In our sample of natural Dalmatian populations, all six pyrethrin compounds in the six populations showed a very similar pattern of accumulation (with a few slight deviations) with increasing content until the peak in FS4, after which the decline begins towards the FS6 or FS7, followed by a stagnation (or a slight increase in the case of jas I and II) until FS8. This synchronicity is consistent with the aforementioned observation from Tasmania and may be attributed to prevailing environmental factors, as seeds from different populations were grown in the same field trial. Another possible explanation could be that the sampled populations share a common genetic background with respect to the genes responsible for the pyrethrin accumulation pattern.

\section{Conclusions}

In the natural Dalmatian pyrethrum populations studied, all six pyrethrin compounds followed very similar accumulation patterns across flower developmental stages (FS1-FS8). There was a rapid accumulation trend of all compounds from FS1 to FS2, followed by the continuous increase till peak in FS4, a general decline to stage FS6 or FS7, and stagnation to FS8. In contrast, there was no regular pattern of change in the pyr I/pyr II ratio and, with few exceptions, no significant differences were observed between the different developmental stages of the populations studied. Our study shows that the flowers of the natural Dalmatian pyrethrum populations are optimal for harvesting at stage FS4, when 2-5 rows of disc flowers open. Maximum values of the total pyrethrin content in the six studied populations ranged from 0.82 to $1.14 \%$ of flower DW, while the highest observed value of the pyr I/pyr II ratio was 1.92. Although the accumulation trends in the different populations were similar, the role of genetic background was indicated by significant differences in the content of pyrethrin compounds between populations at some of the stages studied (between FS1-FS6).

Supplementary Materials: The following supporting information can be downloaded at: https: / / www.mdpi.com/article/10.3390/agronomy12020252/s1, Figure S1: HPLC DAD-UV/VIS chromatogram of standard pyrethrin mixture. Table S1: Results of the analysis of optimal covariance matrix structure model for six pyrethrin compounds, total pyrethrin content, and pyrethrin I/II ratio.

Author Contributions: Conceptualization, M.G.; methodology, M.G. and F.V.; formal analysis, F.V. and Z.Š.; investigation, T.K. and T.N.; writing—original draft preparation, M.G. and N.J.; writingreview \& editing, M.G., N.J., F.V., T.K., T.N. and Z.Š.; visualization, F.V.; funding acquisition, Z.Š. All authors have read and agreed to the published version of the manuscript.

Funding: This research was funded by project KK.01.1.1.01.0005, Biodiversity and Molecular Plant Breeding, at the Centre of Excellence for Biodiversity and Molecular Plant Breeding (CoE CroPBioDiv), Zagreb, Croatia.

Institutional Review Board Statement: Not applicable.

Informed Consent Statement: Not applicable.

Data Availability Statement: Data supporting reported results are available from the corresponding author on reasonable request.

Conflicts of Interest: The authors declare no conflict of interest.

\section{References}

1. Yang, L.; Wen, K.S.; Ruan, X.; Zhao, Y.X.; Wei, F.; Wang, Q. Response of plant secondary metabolites to environmental factors. Molecules 2018, 23, 762. [CrossRef]

2. Li, Y.; Kong, D.; Fu, Y.; Sussman, M.R.; Wu, H. The effect of developmental and environmental factors on secondary metabolites in medicinal plants. Plant Physiol. Biochem. 2020, 148, 80-89. [CrossRef] 
3. Figueiredo, A.C.; Barroso, J.G.; Pedro, L.G.; Scheffer, J.J.C. Factors affecting secondary metabolite production in plants: Volatile components and essential oils. Flavour Fragr. J. 2008, 23, 213-226. [CrossRef]

4. Jones, W.P.; Kinghorn, A.D. Extraction of plant secondary metabolites. In Natural Products Isolation. Methods in Molecular Biology (Methods and Protocols); Sarker, S., Nahar, L., Eds.; Humana Press: Totowa, NJ, USA, 2012; pp. 341-366. ISBN 9781617796234.

5. $\quad$ Nikolić, T. Flora Croatica; Alfa d.d.: Zagreb, Croatia, 2020; Volume 2.

6. Head, S.W. A study of the insecticidal constituents in Chrysanthemum cinerariaefolium. (1) Their development in the flower head. (2) Their distribution in the plant. Pyrethrum Post 1966, 8, 32-37.

7. $\quad$ Ramirez, A.M.; Stoopen, G.; Menzel, T.R.; Gols, R.; Bouwmeester, H.J.; Dicke, M.; Jongsma, M.A. Bidirectional secretions from glandular trichomes of pyrethrum enable immunization of seedlings. Plant Cell 2012, 24, 4252-4265. [CrossRef]

8. Maciver, D.R. Constituents of Pyrethrum Extract. In Pyrethrum Flowers: Production, Chemistry, Toxicology, and Uses; Casida, J.E., Quistad, G.B., Eds.; Oxford University Press: New York, NY, USA, 1995; pp. 108-122.

9. Glynne-Jones, A. Pyrethrum. Pestic. Outlook 2001, 12, 195-198. [CrossRef]

10. Jeran, N.; Grdiša, M.; Varga, F.; Šatović, Z.; Liber, Z.; Dabić, D.; Biošić, M. Pyrethrin from Dalmatian pyrethrum (Tanacetum cinerariifolium/Trevir./Sch. Bip.): Biosynthesis, biological activity, methods of extraction and determination. Phytochem. Rev. 2021, 20, 875-905. [CrossRef]

11. Li, J.; Yin, L.Y.; Jongsma, M.A.; Wang, C.Y. Effects of light, hydropriming and abiotic stress on seed germination, and shoot and root growth of pyrethrum (Tanacetum cinerariifolium). Ind. Crops Prod. 2011, 34, 1543-1549. [CrossRef]

12. Food and Agriculture Organization of the United Nations FAOSTAT. Production: Crops. Available online: https://www.fao.org/ faostat/en/\#data/QCL (accessed on 12 September 2021).

13. Botanical Resources Australia BRA. Available online: https://www.botanicalresources.com/ (accessed on 19 September 2020).

14. Grdiša, M.; Babić, S.; Periša, M.; Carović-Stanko, K.; Kolak, I.; Liber, Z.; Jug-Dujaković, M.; Satovic, Z. Chemical diversity of the natural populations of Dalmatian Pyrethrum (Tanacetum cinerariifolium/Trevir./Sch.Bip.) in Croatia. Chem. Biodivers. 2013, 10, 460-472. [CrossRef]

15. Varga, F.; Jeran, N.; Šatović, Z.; Biošić, M.; Grdiša, M. High diversity of natural Dalmatian pyrethrum based on pyrethrin composition at intra- and interpopulation level. Phytochemistry 2021, 192, 112934. [CrossRef]

16. Morris, S.E.; Davies, N.W.; Brown, P.H.; Groom, T. Effect of drying conditions on pyrethrins content. Ind. Crops Prod. 2006, 23, 9-14. [CrossRef]

17. Bhat, B.K. Breeding Methodologies Applicable to Pyrethrum. In Pyrethrum Flowers: Production, Chemistry, Toxicology, and Uses; Casida, J.E., Quistad, G.B., Eds.; Oxford University Press: New York, NY, USA, 1995; pp. 67-94.

18. Grdiša, M.; Liber, Z.; Radosavljević, I.; Carović-Stanko, K.; Kolak, I.; Satovic, Z. Genetic diversity and structure of Dalmatian pyrethrum (Tanacetum cinerariifolium Trevir./Sch./Bip., Asteraceae) within the Balkan refugium. PLoS ONE 2014, 9, e105265. [CrossRef]

19. Parlevliet, J. The genetic variability of the yield components in the Kenyan pyrethrum populations. Euphytica 1974, 23, 377-384. [CrossRef]

20. Bhat, B.K.; Menary, R.C. Genotypic and phenotypic correlation in Pyrethrum, (Chrysanthemum cinerariaefolium Vis), and their implication in selection. Pyrethrum Post 1986, 16, 61-65.

21. Pandita, P.N.; Bhat, B.K. Correlations in phenotypic traits of Pyrethrum (Chrysanthemum cinerariaefolium Vis). Pyrethrum Post 1986, 16, 93-94.

22. Singh, S.P.; Sharma, J.R.; Rajeswara Rao, B.R.; Sharma, S.K. Genetic improvement of pyrethrum. II. Parent-offspring correlation and progeny performance. Pyrethrum Post 1988, 17, 8-11.

23. Ambrožič Dolinšek, J.; Kovač, M.; Žel, J.; Camloh, M. Pyrethrum (Tanacetum cinerariifolium) from the Northern Adriatic as a potential source of natural insecticide. Ann. Ser. Hist. Nat. 2007, 17, 39-46.

24. Wandahwa, P.; Van Ranst, E.; Van Damme, P. Pyrethrum (Chrysanthemum cinerariaefolium Vis.) cultivation in West Kenya: Origin, ecological conditions and management. Ind. Crops Prod. 1996, 5, 307-322. [CrossRef]

25. Ban, D.; Sladonja, B.; Lukić, M.; Lukić, I.; Lušetić, V.; Ganić, K.K.; Žnidarčič, D. Comparison of pyrethrins extraction methods efficiencies. Afr. J. Biotechnol. 2010, 9, 2702-2708. [CrossRef]

26. Gallo, M.; Formato, A.; Ianniello, D.; Andolfi, A.; Conte, E.; Ciaravolo, M.; Varchetta, V.; Naviglio, D. Supercritical fluid extraction of pyrethrins from pyrethrum flowers (Chrysanthemum cinerariifolium) compared to traditional maceration and cyclic pressurization extraction. J. Supercrit. Fluids 2017, 119, 104-112. [CrossRef]

27. Kiriamiti, H.K.; Camy, S.; Gourdon, C.; Condoret, J.S. Pyrethrin exraction from pyrethrum flowers using carbon dioxide. J. Supercrit. Fluids 2003, 26, 193-200. [CrossRef]

28. Nagar, A.; Chatterjee, A.; Ur Rehman, L.; Ahmad, A.; Tandon, S. Comparative extraction and enrichment techniques for pyrethrins from flowers of Chrysanthemum cinerariaefolium. Ind. Crops Prod. 2015, 76, 955-960. [CrossRef]

29. Pan, W.H.T.; Chang, C.C.; Su, T.T.; Lee, F.; Fuh, M.R.S. Preparative supercritical fluid extraction of pyrethrin I and II from pyrethrum flower. Talanta 1995, 42, 1745-1749. [CrossRef]

30. Beckley, V.A. Pyrethrum drying. Pyrethrum Post 1952, 1, 9-11.

31. Ngugi, C.W.; Ikahu, J.M.K. The effect of drying temperature on pyrethrins content in some pyrethrum clones. Pyrethrum Post 1990, 18, 18-21. 
32. Suraweera, D.D.; Groom, T.; Taylor, P.W.J.; Jayasinghe, C.S.; Nicolas, M.E. Dynamics of flower, achene and trichome development governs the accumulation of pyrethrins in pyrethrum (Tanacetum cinerariifolium) under irrigated and dryland conditions. Ind. Crops Prod. 2017, 109, 123-133. [CrossRef]

33. Parlevliet, J.E. The Effect of Picking Interval and Flower Head Development on the Pyrethrins Content of Different Pyrethrum Clones. Pyrethrum Post 1970, 10, 10-14.

34. Bhat, B.K.; Menary, R.C. Genotypic and Phenotypic Variation in Floral development of different Clones of Pyrethrum (Chrysanthemum cinerariaefolium Vis). Pyrethrum Post 1984, 15, 99-103.

35. Ikahu, J.M.; Ngugi, C.W. Investigations into yield losses of some pyrethrum clones through picking of flowers improper stage of development. Pyrethrum Post 1989, 17, 56-59.

36. Notcutt, L.A. Oil gland count as an approximate means of evaluating Pyrethrum flowers. Pyrethrum Post 1955, 3, 9-14.

37. Bhat, B.K.; Menary, R.C. Scanning electron microscopic study of oil glands in pyrethrum flowers. Pyrethrum Post 1979, 15, 11-15.

38. Suraweera, D.D.; Groom, T.; Nicolas, M.E. Pattern of pyrethrin accumulation, achene and trichome development in relation to pattern of flower development in pyrethrum. Acta Hortic. 2017, 1169, 93-100. [CrossRef]

39. Head, S.W. Composition of Pyrethrum Extract and Analysis of Pyrethrins. In Pyretrum: The Natural Insecticide; Casida, J.E., Ed.; Academic Press: New York, NY, USA, 1973; pp. 25-53. ISBN 978-0-12-162950-2.

40. Potts, W.; Menary, R. Research Report on Pyrethrum; University of Tasmania: Hobart, Australia, 1987.

41. Fulton, D. Agronomic and Seed Quality Studies in Pyrethrum Tanacetum cinerariaefolium Sch. Bip. Ph.D. Thesis, University of Tasmania, Hobart, Australia, 1998.

42. Beckley, V.A.; Gnadinger, C.B.; Ireland, F. Pyrethrum flowers Kenya, a better source. Ind. Eng. Chem. 1938, 30, 835-838. [CrossRef]

43. Gnadinger, C.B.; Corl, C.S. Studies on pyrethrum flowers. II. The relation between maturity and pyrethrin content. J. Am. Chem. Soc. 1930, 52, 680-684. [CrossRef]

44. Babić, S.; Grdiša, M.; Periša, M.; Ašperger, D.; Šatović, Z.; Kaštelan-Macan, M. Ultrasound-assisted extraction of pyrethrins from pyrethrum flowers. Agrochimica 2012, 56, 193-206.

45. Littell, R.C.; Pendergast, J.; Natarajan, R. Modelling covariance structure in the analysis of repeated measures data. Stat. Med. 2000, 19, 1793-1819. [CrossRef]

46. Groom, K. An Investigation of Breeding Methods Applicable to Tasmanian-Grown Pyrethrum. Ph.D. Thesis, University of Tasmania, Hobart, Australia, 2003.

47. Rivera, S.B.; Swedlund, B.D.; King, G.J.; Bell, R.N.; Hussey, C.E.; Shattuck-Eidens, D.M.; Wrobel, W.M.; Peiser, G.D.; Poulter, C.D. Chrysanthemyl diphosphate synthase: Isolation of the gene and characterization of the recombinant non-head-to-tail monoterpene synthase from Chrysanthemum cinerariaefolium. Proc. Natl. Acad. Sci. USA 2001, 98, 4373-4378. [CrossRef]

48. Ramirez, A.; Yang, T.; Bouwmeester, H.J.; Jongsma, M.A. A trichome-specific linoleate lipoxygenase expressed during pyrethrin biosynthesis in pyrethrum. Lipids 2013, 48, 1005-1015. [CrossRef]

49. Head, S.W. A Study of the Insecticidal Constituents of Chrysanthemum cinerariaefolium (3) Their Composition in Different Pyrethrum Clones. Pyrethrum Post 1967, 9, 3-7. 